\title{
Friction and Wear of GUR 1020 Medical Grade Uhmwpe Polymer at Dry Environmental Condition
}

\author{
A Mimaroglu ${ }^{1}$, H Unal ${ }^{2}$, M Sumer $^{1}$, A Ozel ${ }^{1, *}$ \\ ${ }^{1}$ Faculty of Engineering, University of Sakarya, Esentepe Campus, Turkey \\ ${ }^{2}$ Faculty of Technology, University of Sakarya, Esentepe Campus, Turkey
}

Copyright (C) 2015 by authors, all rights reserved. Authors agree that this article remains permanently open access under the terms of the Creative Commons Attribution License 4.0 International License

\begin{abstract}
In engineering applications when materials start sliding against each other the problem of friction and wear appears. In the case of polymers the friction between them can be attributed to two main mechanisms: deformation and adhesion. One of the important application fields for polymers is the medical engineering. In this field, the UHMWPE polymer is one of the important candidant polymer material. In this investigation, the friction and wear performance of GUR 1020 medical grade UHMWPE polymer under dry sliding conditions is evaluated. The sliding experiments were carried out on a pin-on-AISI stainless steel disc arrangement. Wear tests were carried out under room temperature, 50, 100 and $150 \mathrm{~N}$ load values and at $0.50,1.0$ and $2.0 \mathrm{~m} / \mathrm{s}$ sliding speed conditions. The results show that the coefficient of friction for GUR 1020 medical grade UHMWPE polymer is significantly influenced by applied load, sliding speed values. Furthermore, the coefficient of friction and specific wear rate increases with the increase in applied load and sliding speed values. The specific wear rate values for GUR 1020 medical grade UHMWPE polymer under dry condition is at the order of $8 \times 10^{-14} \mathrm{~m}^{2} / \mathrm{N}$. The friction coefficients vary between 0.12 and 0.20 . Finally, the wear mechanism includes abrasive and adhesive processes.
\end{abstract}

Keywords Medical Grade UHMWPE, Tribology, Dry

\section{Introduction}

Ultra-high molecular weight polyethylene (UHMWPE) is useful thermoplastic polymer both for industrial and biomaterials applications. The material has been used successfully as a bearing material in engineering applications as well as for total joint replacements. This is due to its excellent properties, such as bio-compatibility, chemical stability, high impact strength, high wear resistance, and low friction [1-5]. Thus, understanding, enhancing tribological and mechanical properties of UHMWPE will be important to prolong the longevity of joint replacement components and alleviate the pain of the patients. In the past, studies had been carried out on characteristics of UHMWPE polymer. Some were as a general review [6-8] and some others were extensive studies to improve UHMWPE wear resistance by tailoring the material with fiber reinforcement [9-11], cross-linking [12-13] and grafting [14]. Although, these factors are important in influencing the tribological characteristics of UHMWPE polymer, but other factors such as applied load, sliding speed and lubrication are also important [15-18].

The purposes of this investigation are to clarify the tribological characteristic of GUR 1020 medical grade UHMWPE polymer sliding against stainless steel under dry sliding, distilled water and egg albumen lubricated conditions and to evaluate the level of influence of applied load and sliding speed values. Friction and wear tests against AISI 304L stainless steel disc were carried out on a pin-ondisc arrangement. These tests were at room temperature under 50, 100 and $150 \mathrm{~N}$ load values and at 0.5, 1.0 and 2.0 $\mathrm{m} / \mathrm{s}$ sliding speeds.

\section{Experimental Details}

\section{Materials}

Flat-ended pins with $6 \mathrm{~mm}$ in diameter of GUR 1020 medical grade UHMWPE polymer were used in this investigation. AISI 304L stainless steel discs were machined to $10 \mathrm{~mm}$ thickness and $100 \mathrm{~mm}$ diameter, and was grind to $0.09 \mu \mathrm{m}$ Ra surface roughness and with a hardness value of $297 \mathrm{HV}$. The specific wear test conditions as follows: ambient temperature is about $19 \pm 2{ }^{\circ} \mathrm{C}$, sliding speed: $0.5,1.0$, $1.5,2.0 \mathrm{~m} / \mathrm{s}$, applied load; $50,100,150 \mathrm{~N}$ and relative humidity: $52 \pm 2$.

The tribometer and tests

A pin-on-disc apparatus connected to a computer was used to evaluate the friction coefficient of the GUR 1020 medical grade UHMWPE polymer against steel under dry sliding 
conditions. Before each tests the flat-ended polymer pins and AISI 304L stainless steel discs were cleaned with alcohol and acetone and then installed in the pin-on-disc apparatus. The friction and wear tests were performed at room temperature, sliding speeds of $0.5,1.0$ and $2.0 \mathrm{~m} / \mathrm{s}$ and applied load values from 50 to $150 \mathrm{~N}$. These wide ranges of test condition were decided to cover the severe working condition of the knee joint such as jogging. These tests were carried out under dry sliding conditions. Figure 1 shows a schematic diagram of the pin-on-disc wear test apparatus that was designed and used for this work.

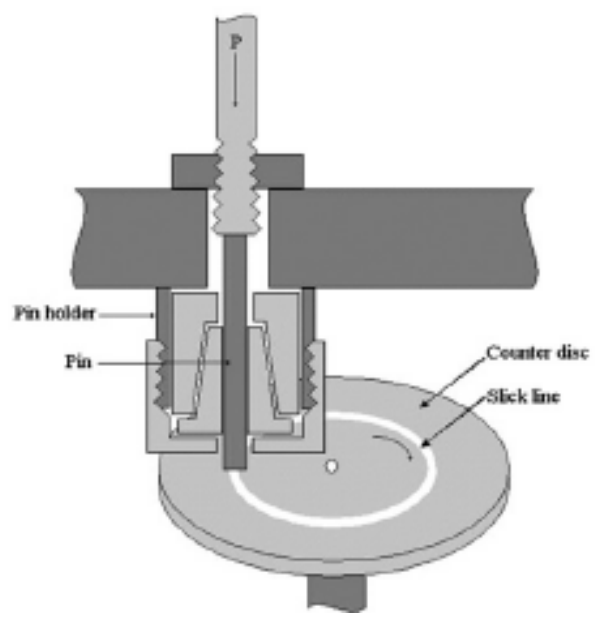

Figure 1. Schematic diagram of the pin-on-disc wear test apparatus

As shown in this figure, the rig consists of a stainless steel table which is mounted on a turntable, a variable speed motor which provides the rotational motion to the turntable, hence to the disk sample and a pin sample holder which is rigidly attached to a pivoted loading arm. This loading arm is supported in bearing arrangements to allow loads to be applied to the specimen. During the test, friction force was measured by a transducer mounted on the loading arm. The friction force readings were taken as the average of 35 readings every one sec for a period of a $66 \mathrm{~min}$ test time, which ensures the sufficient sliding distance within the steady state wear region. For this purpose a microprocessor controlled data acquisition system was used. Finally, the specific wear rates were calculated from mass loss and the represented. Sliding wear data is the average of at least three runs.

\section{Results and Discussions}

Figure 2 illustrates the variation of friction coefficients of UHMWPE polymer with applied load tested at $0.5,1.0,1.5$ and $2.0 \mathrm{~m} / \mathrm{s}$ sliding speeds and at dry sliding conditions. It was clear from Figure 2 that the coefficient of friction values for UHMWPE polymer at dry sliding conditions increases with the increase in applied load values. This figure also shows that there is an average of $15 \%$ increase in friction coefficient value for a $200 \%$ change in load values under dry sliding condition. As it is known that GUR 1020 medical grade UHMWPE polymer is a visco-elastic material, the variation of friction coefficient with the load follows the

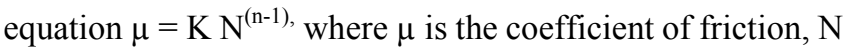
is the applied load, $\mathrm{K}$ is a constant and $\mathrm{n}$ is also a constant, with a value between $2 / 3$ and 1 . According to this equation, the friction coefficient decreases with load increase. But when the load increases to the critical load value of the GUR 1020 medical grade UHMWPE polymer, the friction and wear will increase sharply. This behavior can be attributed to the fact that the frictional heat raises the temperature of the friction surfaces, which lead to relaxation of polymer molecule chains.

Figure 3 illustrates the variation of specific wear rate of UHMWPE polymer with sliding speed, tested at 50, 100 and $150 \mathrm{~N}$ applied loads at dry sliding conditions. This figure shows that the specific wear rate values increases with the increasing in sliding speed. This is in agreement with the results of Wang and $\mathrm{Li}$ (1999). As the sliding speed is increased by $300 \%$, from 0.5 to $2.0 \mathrm{~m} / \mathrm{s}$, there is an average of 66 and $50 \%$ increase in specific wear rate of UHMWPE polymer at dry sliding conditions.

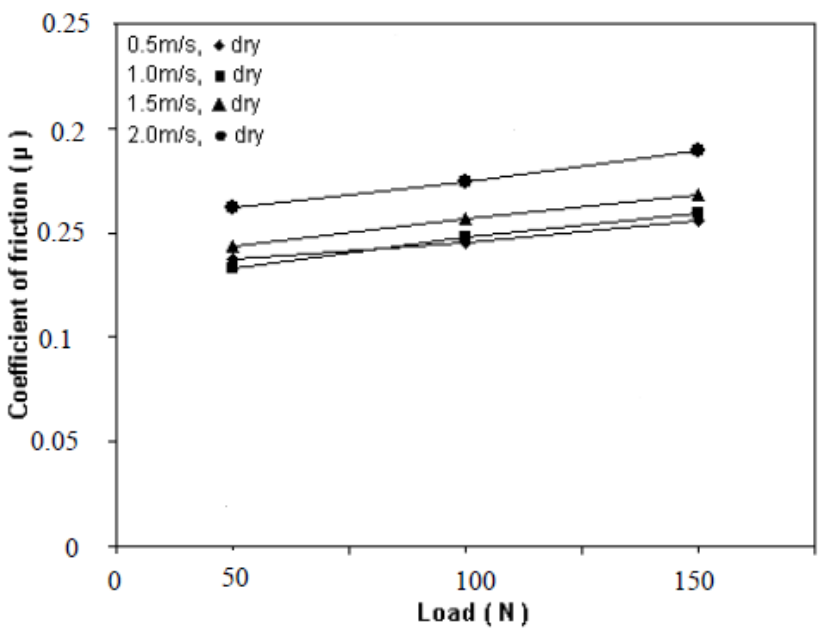

Figure 2. The relationship between coefficient of friction and applied load values of medical grade UHMWPE under dry sliding conditions

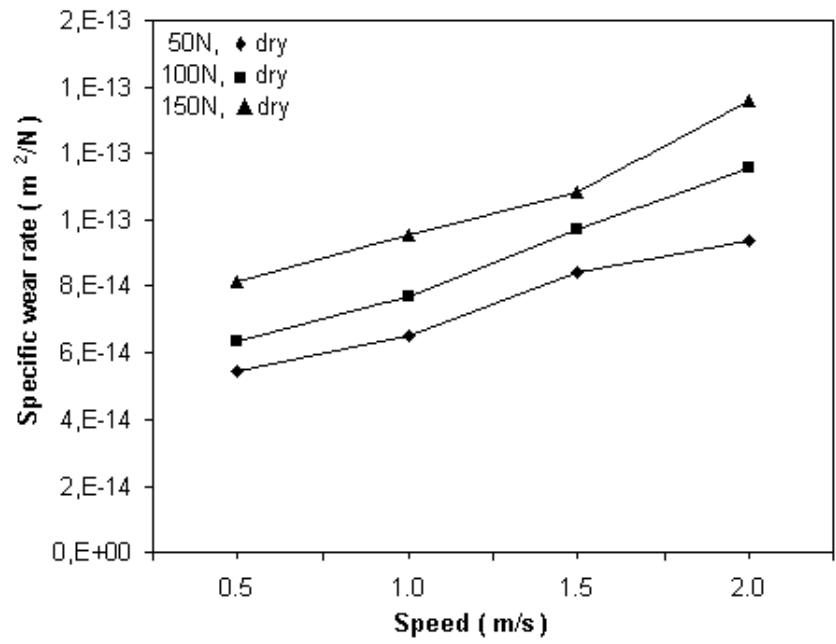

Figure 3. The relationship between specific wear rate and sliding speed values of medical grade UHMWPE under dry sliding conditions 
The optical microscopy examination of worn surfaces of GUR 1020 UHMWPE polymer pin against AISI 304L stainless steel disc at $150 \mathrm{~N}$ applied load and at $1.0 \mathrm{~m} / \mathrm{s}$ sliding speed test for dry sliding conditions are given in Figure $4 \mathrm{a}$. In this figure the worm surface is wrinkled with wavy morphology and the wrinkling is denser with deep grooves for dry condition. This is due to the high temperature reaching the polymer surface. Higher temperatures in the polymer surfaces result in softening the polymer surface and wrinkling present on the surface.

Figure $4 \mathrm{~b}$ shows the worn surface of counterface AISI 304L stainless steel disc. This figure shows the presence of some thin patches of UHMWPE polymer transfer film on the steel counter-face both at dry sliding condition. Generally, the presence of wrinkling on pin surface and the transfer film patches on the disc surface suggest the presence of abrasive and adhesive wear mechanisms.

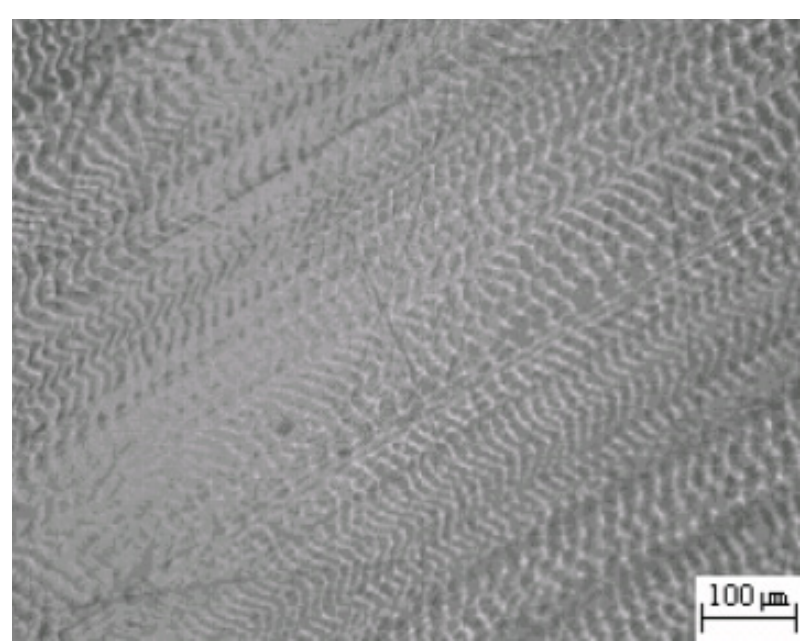

a)

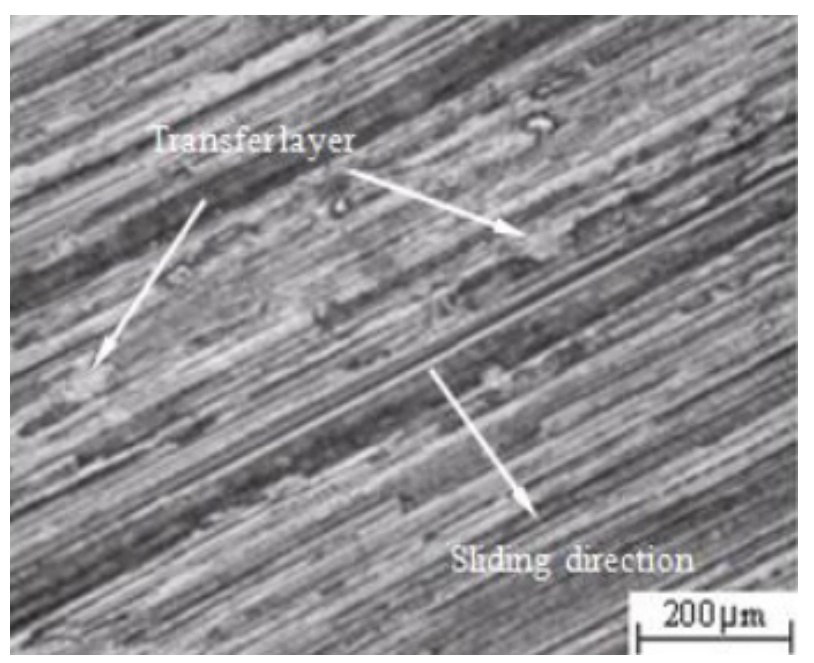

b)

Figure 4. The optical micrographs of the worn surfaces of a) UHMWPE pin b) AISI $316 \mathrm{~L}$ SS counter-face disc under dry sliding conditions

\section{Conclusions}

1. The friction coefficients vary between 0.12 and 0.20 under dry sliding condition for GUR 1020 medical grade UHMWPE polymer at the range of applied load and sliding speed.

2. The average specific wear rates for GUR 1020 medical grade UHMWPE polymer under dry sliding condition is in the order of $8 \times 10^{-14} \mathrm{~m}^{2} / \mathrm{N}$.

3. The specific wear rate for UHMWPE is significantly influenced by applied load and sliding speed values.

4. Wear mechanism includes abrasive and adhesive processes.

\section{REFERENCES}

[1] B. J., Briscoe, S. K. ,Sinha, J. Engrng. Tribol. Proc. Instn Mech. Engrs part J., 216, 401, 2002.

[2] E.M., Brach Del Prever, A., Bistolfi, P., Bracco, L., Costa, J. Orthop. Traumatol., 10(1), 1, 2009.

[3] Z.M., Jin, M., Stone, E., Ingham, J. Fisher Biotribology. Curr. Orthop., 20, 32, 2006.

[4] S.M., Kurtz, O.K., Muratoglu, M., Evans, A.A., Edidin., Biomaterials 20: 1659, 1999.

[5] X., Dangsheng, G., Shirong, Wear, 8780, 1, 2001.

[6] T.M., McGloughlin, A.G., Kavanagh, Proc Instn Mech Engrs, part B., 214, 349, 2000.

[7] A., El-Domiaty, M.A.F., El-Fadaly, J.MEPEG, 11(5), 577, 2002 .

[8] P.S., Walker, D.M., Ben, M.J., Askew, J Pugh, Eng. Med., 10(1), 33, 1981 .

[9] N., Chang, A. Bellare, R.E., Cohen, M., Spector, Wear, 241,109, 2000 .

[10] L., Fang, Y. Leng, P. Gao, Biomater., 26(17), 3471, 2005.

[11] X. Dangsheng, Mater. Lett., 59. 175,2005.

[12] G. Lewis, Biomater., 22:,371, 2001.

[13] S.M. Kurtz, M.L., Villarraga, M.P., Herr, J.S., Bergstrom, C.M., Rimnac, A.A., Edidin, Biomater., 23, 3681, 2002.

[14] T. Moro, Y. Takatori, K. Ishihara, T. Konno, Y. Takigawa, T. Matsushita, U.I., Chung, K. Nakamura, H., Kawaguchi, Nature Mater., 3(1), 829, 2004.

[15] M. Chandrasekaran, N.L., Loh, Wear. 250, 237, 2001.

[16] M.P., Gispert, A.P., Serro, R., Colaco, B. Saramago, Wear. 260, 149, 2006.

[17] T. Stewart, Z.M., Jin, D. Shaw, D.D., Auger, M. Stone, J. Fisher, Proc. Instn Mech. Engrngs, Part H: J. Engnrg Med., 209,225, 1995.

[18] W. Gang, Z. Chunhua, Z. Xinze, Technical Sessions-Proceedings of CIST2008\&ITS-IFToMM2008 Beijing, China, 2008. 